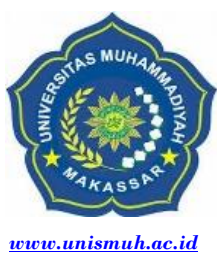

Jurnal Equilibrium Pendidikan Sosiologi

Jurnal Equilibrium Pendidikan Sosiologi

http://journal.unismuh.ac.id/index.php/equilibrium

Vol V Desember No. 22017

\title{
Interaksi Keberagamaan Dakwah Muhammadiyah di Kota Makassar
}

\author{
Nursalam ${ }^{1)} \&$ Suardi $^{2)}$ \\ Universitas Muhammadiyah Makassar \\ nursalam.h@unismuh.ac.id ${ }^{1)}$ \& suardi@unismuh.ac.id ${ }^{2)}$
}

\begin{abstract}
This research is funded by the Muhammadiyah grant scheme. The purpose of this research in general is to examine the resources of Muhammadiyah da'wah. The type of this research is qualitative, the determination of informant research done by purposive sampling technique and snowball sampling. Data collection techniques through participant observation, in-depth interviews, documentation and participatory, research data will be analyzed through data reduction, display data, conclusion drawing and conclusion drawing. Data validity technique uses internal validity test, external validity, Dependency. Certainty / objectivity, and Triangulation (source, technique and time). The result of the research shows that to become dai Muhammadiyah that is (1) is a cadre, (2) active in organization, (3) recommendation from Branch or branch leader, (4) pass administration selection, (5) pass the reading ability test of Qur'an and the ability to perform lectures or khutbah. Competence must be owned by dai Muhammadiyah that is (1) understand Al Qur'an and hadith, (2) have science and education, (3) follow training. The form of the dai Muhammadiyah model is divided into three forms namely the serious da'wah model, the model of da'wah homoris and the model of serious and humorous combined da'wah. Propagation material muhammadiyah includes 7 material that is aqidah, morals, dates, general studies, special studies and Masail fighiyyah. The role of dai includes the mastery of social media, regeneration of dai, understanding of da'wah maps, efficiency of time, conduct study and reading.

Keywords: Interaction, Dakwah, Muhammadiyah
\end{abstract}

\begin{abstract}
Abstrak. Penelitian ini di danai oleh skema hibah Muhammadiyah. Tujuan penelitian ini secara umum adalah untuk meneliti sumber daya dakwah Muhammadiyah. Jenis penelitian ini adalah kualitatif, penentuan informan penelitian dilakukan dengan teknik purposive sampling dan snowball sampling. Teknik pengumpulan data melalui observasi partisipan, wawancara mendalam, dokumentasi dan partisipatif, data penelitian akan dianalisi melalui tahapan data reduction, display data, penarikan kesimpulan dan conclusion drawing. Teknik keabsahan data menggunakan uji validitas internal, validitas eksternal, Kebergantungan. Kepastian/objektivitas, dan Triangulasi (sumber, teknik dan waktu). Hasil penelitian menunjukkan bahwa untuk menjadi dai Muhammadiyah yaitu (1) merupakan kader, (2) aktif dalam Organisasi, (3) rekomendasi dari Pimpinan Ranting atau Cabang, (4) lulus seleksi administrasi, (5) lulus tes kemampuan membaca Al Qur'an dan tes kemampuan melakukan ceramah atau khutbah. Kompetensi yang harus dimiliki oleh dai Muhammadiyah yaitu (1) memahami Al Qur'an dan hadits, (2) memiliki ilmu pengetahuan dan pendidikan, (3) mengikuti pelatihan. Bentuk model dai Muhammadiyah terbagi menjadi tiga bentuk yaitu model dakwah serius, model dakwah homoris dan model dakwah gabungan serius dan humoris. Materi dakwah muhammadiyah mencakup 7 materi yaitu aqidah, akhlak, tarikh, kajian umum, kajian khusus dan Masail fiqhiyyah. Peran dai meliputi penguasaan media sosial, regenerasi dai, pemahaman peta dakwah, efisiensi waktu, melakukan kajian dan membaca.
\end{abstract}

Kata Kunci: Interaksi, Dakwah, Muhammadiyah 


\section{PENDAHULUAN}

Islam di Indonesia terkhusus di Sulawesi Selatan tidak dapat terlepas dari Muhammadiyah dan NU (Nahdlatul Ulama). Kedua ormas ini turut mewarnai sejarah Indonesia terutama pada masa pra-kemerdekaan. Sepanjang perjalanan kedua organisasi Islamterbesar ini, senantiasa diwarnai koorporasi, kompetisi, sekaligus konfrontasi. Kajian Muhammadiyah dan NU di Indonesia selalu melibatkan harapan dankekhawatiran lama yang mencekam, karena wilayah pembahasan ini penuhromantisme masa lalu yang sarat emosi dan sentimen historis yang amat sensitif. Sekedar contoh, sering dinyatakan, kelahiran NU tahun 1926 merupakan reaksidefensif atas berbagai aktivitas kelompok reformis, Muhammadiyah dan Serekat Islam, meski bukan satu-satunya alasan. Muhammadiyah melalui gerakan pembaharuan keagamaan, maupun NU dalam proses dakwah kultural. Dalam banyak hal, tradisi Islam lokal sering diposisikan sebagai berseberangan secara diametrikal dengan gerakan pembaharuan Islam. (Nur Syam $2003: 8$ ) NU dan Muhammadiyah adalah sebuah organisasi masyarakat yang bergerak pada bidang keagamaan lebih tepatnya sebuah organisasi masyarakat agama Islam yang ada di Indonesia. Kedua organisasi ini adalah organisasi Islam yang ada di beberapa tempat khususnya di kota-kota besar. Seringkali kita mendapatkan atau melihat diberbagai media terjadinya perbedaan prinsip serta tata cara kedua ormas ini dalam melakukan ibadah. Sehingga banyak anggapan negatif (streotipe) bagi kedua ormas tersebut sebagai organisasi yang berbeda dan tidak mungkin dapat bersatu bahkan perbedaan tersebut bisa melahirkan konflik, faktor yang lain karena keduanya memiliki metode dakwah yang berbeda antara satu dengan yang lain.

Penelitian tentang interaksi keagamaan Muhammadiyah perna dilakukan oleh peneliti sebelumnya yaitu Muhadi (2013) melakukan penelitian tentang interaksi social antar umat muslim dalam keberagamaan (studi terhadap interaksi social masyarakat Desa Giri Asih Kabupaten Gunung Kidul Yogyakarta) hasil penelitiannya menunjukkan pola interaksi social antar umat muslim di Desa Giri adalah adalah interaksi yang bersifat asosiatif yaitu masyarakat yang hidup dengan gotong royong, tolong menolong, berupa kerja sama, akomodasi, asimilasi sehingga terlihat kehidupan yang sangat sederhana memperkokoh integrasi masyarakat, pemahaman budaya bersama merupakan dasar terbentuknya kerukunan di masyarakat sehingga tercipta hidup yang serasi dan terjaga dari penyimpangan. Tradisi lokal menjadi penyeimbang terciptanya kerukunan antar umat muslim dalm pluralitas paham keagamaan di Giri Asih. Iwan Setiawan (2015) melakukan penelitian tentang interaksi social anatar kelompok tradisi dan reformis islam di tingkat desa (studi kasus kelompok pengajian muhammdiyah dan kelompok pengajian Nahdlatul Ulama (NU) di Desa Margasari Kecamatan Margasari Kabupaten Tegal Provinsi Jawa Tengah. Hasil penelitiannya mendiskripsikan bahwa sikap anggota pengajian Muhammadiyah terhadap kelompok pengajian kelompok NU bersifat akomodatif. Dengan demikian interaksi yang terjalin diantara mereka membentuk proses social yang mendekatkan (asosiatif) yang kemudian membawa dalam kehidupan yang harmonis diantara mereka dalam masyarakat Desa Margasari. Kerukunan pengajian Muhammadiyah terhadap kelompok pengajian kelompok NU dapat dijadikan teladan dan patut dikembangkan lebih luas. Kesedian anggota kelompok pengajian untuk dapat saling menghargai perbedaan sebagai sesame warga sehingga kerukunan di antara warga Desa Margasari yang tidak membeda-bedakan agama ataupun golongan. Kedua penelitian tersebut menjelaskan tentang interaksi Muhammadiyah dalam aspek gotong royong, tolong menolong dan aspek saling menghargai dalam kelompok pengajian, yang membedakan dengan penelitian yang akan dilakukan oleh peneliti adalah fokus penelitian yang berfokus pada sumber daya dakwah muhammadiyah dan peran dai, dai'yah dan Muballighot dalam meningkatkan kulaitas dakwah Muhammadiyah. 


\section{METODE PENELITIAN}

Jenis penelitian ini adalah kualitatif melalui pendekatan studi kasus di kota Makassar,.instrumen penelitian adalah peneliti sendiri (human instrumen) dengan menggunakan alat bantu berupa pedoman wawancara, instrument dokumentasi dan catatan observasi, alat perekam dan kamera. Pemilihan informan dilakukan secara purposive sampling dan snowball sampling. Fokus penelitian dalam penelitian ini adalah interaksi dalam aspek dakwah yang dilakukan oleh dai, daiyah, muballighot Muhammadiyah. Jenis data terdiri dari data primer dan data sekunder. Teknik pengumpulan data menggunakan metode observasi, wawancara mendalam, dokumentasi dan partisipatif. Analisis data dilakukan melalui tahapan reduksi data (data reduction), penyajian data (display data), verivication dan penarikan kesimpulan. Sedangkan teknik keabsahan data melalui (1) uji credibility/validitas internal yang meliputi perpanjangan pengamatan (prolonged engagement) dan meningkatkan ketekunan (persistent observation), (2) transferability/ validitas eksternal, (3) Kebergantungan (dependability/ reliabilitas), (4) Kepastian/ objektivitas (confirmability), dan (5) Triangulasi (sumber, teknik dan waktu).

\section{PEMBAHASAN}

\section{Kompetensi $D a^{\prime} i$ Muhammadiyah di Kota}

\section{Makassar}

Kompetensi yang harus dimiliki oleh seorang da'i di Kota Makassar terdiri dari berbagai kompetensi diantaranya adalah :

a. Memahami Al-Qur'an dan Al Hadist

Al-Qur'an dan Al Hadist yang merupakan pedoman kehidupan bagi setiap umat Islam lebih khusus dalam hal ini adalah $d a^{\prime} i$ muhammadiyah. Hal tersebut yang dijadikan sebagai pedoman dalam hidup dan pedoman dalam melakukan dakwah kepada masyarakat. Dengan berpedoman pada keduanya maka diharapkan setiap $d a^{\prime} i$ muhammadiyah dalam menyampaikan dakwah tidak keluar dari tuntunan Al-Qur'an dan Al Hadist. karena al-
Qur'an merupakan kalam Allah SWT yang diberikan kepada Nabi Muhammad saw melalui Malaikat Jibril dan hadist merupakan segala ucapan, dan perbuatan nabi Muhammad SAW. Hal tersebut perlu dilakukan karena Muhammadiyah merupakan tokoh sentral Agama yang memiliki otoritas dalam menafsirkan dan memahami ajaran agama dalam hal Al-Qur'an dan Al Hadist (Kholis, M. (2015).

b. Memiliki Ilmu Pengetahuan dan Pendidikan Untuk menunjang kompetensi yang pertama, maka diperlukan ilmu pengetahuan untuk mengkaji dan memahami Al-Qur'an dan Al Hadist. Pengetahuan tersebut dapat diperoleh secara alami maupun secara terencana yaitu melalui proses pendidikan (Sariningrum, E. 2009). Sehingga setiap $d a^{\prime} i$ muhammadiyah di Kota Makassar diharuskan untuk memiliki jenjang pendidikan lebih khusus adalah pendidikan yang berkaitan dengan dakwah Muhammadiyah, seperti merupakan alumni sekolah atau perguruan tinggi yang memiliki Jurusan yang berkaitan dengan dakwah Muhammadiyah, selain itu diharapkan memiliki ilmu pengetahuan yang lain yang dapat menunjang dakwah Muhammadiyah seperti halnya memiliki ilmu sosial, psikologi, budaya dan ilmu yang lain yang dapat membantu memahami karakteristik jamaah/audiensi dan medan sosial tempat $d a^{\prime} i$ Muhammadiyah melakukan dakwah Muhammadiyah.

c. Mengikuti Pelatihan

Tahap awal menghasilkan kader ulama, pemimpin, mubalig dan pendidik melalui pendidikan dan pelatihan, belajar kemuhammadiyahan lebih mendalam, mencakup historis, organisatoris, dan ideologis, serta mampu memeragakan nilai muhammadiyah itu sendiri (Azhar, A., Wuradji, W., \& Siswoyo, D. 2016). Setiap $d a^{\prime} i$ Muhammadiyah di Kota Makassar diharuskan untuk selalu mengikuti berbagai pelatihanpelatihan $d a^{\prime} i$ dan pelatihan mubaligh yang diadakan oleh Muhammadiyah seperti yang dilakukan oleh Pimpinan Daerah Pemuda 
Muhammadiyah (PD PM) Kota Makassar, Ikatan Pelajar Muhammadiyah Sulawesi Selatan, Majelis Pemberdayaan Masyarakat Pimpinan Wilayah Muhammadiyah Sulawesi selatan, Pendidikan Ulama Tarjih Muhammadiyah dan Pusat Dakwah Islamiyah Muhammadiyah Kota Makassar. Selain itu ada beberapa $d a^{\prime} i$ Muhammadiyah yang pernah mengikuti pelatihan $d a^{\prime} i$ yang dilakukan oleh berbagai pusat dakwah diluar Muhammadiyah seperti pelatihan $d a^{\prime} i$ di Mesjid Al-Markas Kota Makassar, hal tersebut dilakukan agar setiap $d a^{\prime} i$ Muhammadiyah memiliki keterampilan, pengetahuan dan akhlak yang baik dalam menyampaikan dakwah di tengah-tengah masyarakat yang heterogen di Kota Makassar. Hasil dari pelatihan tersebut selain mendapatkan ilmu, keterampilan dan sikap dalam berdakwah, para da'i juga mendapatkan sertifikat, sebagai bukti perna mengikuti pelatihan da'i atau muballigh. Pelatihan yang lain yang dapat diberikan seperti pelatihan manejemen dakwah, bimbingan dan penyuluhan rohani, bakti sosial dan kesehatan, pelatihan kewirausahaan di pondok-pondok pesantren, pelatihan keterampilan, bantuan kepada daerah yang terkena bencana, pemberian beasiswa, buka puasa bersama, penanggulangan masalah remaja, terawih keliling, bazar sembako murah, dan lain sebagainya (Asroni, A., Yusup, M., \& Sofia, A. 2015).

\section{Bentuk Model dakwah}

Berbagai bentuk model dakwah yang dilakukan oleh para $d^{\prime} i$ Muhammadiyah di Kota Makassar, yang terbagi menjadi tiga bentuk dakwah yaitu :

a. Model dakwah serius

Model dakwah ini merupakan model dakwah yang paling banyak diterapkan oleh $d a^{\prime} i$ muhammadiyah di Kota Makassar hal tersebut sesuai dengan anjuran Pimpinan Muhammadiyah agar menyampaikan dakwah secara serius, selain itu para $d a^{\prime} i$ beranggapan bahwa model dakwah tersebut sangat efektif dan cocok untuk menyampaikan ajaran-ajaran Islam.

d. Model dakwah humoris

Di dalam buku Jalaluddin Rakhmat teori teknik humor yang demikian itu adalah Puns yaitu mempermainkan kata-kata yang mempunyai makna ganda (IImi, M. 2013). Model dakwah ini merupakan model dakwah menyampaikan materi dakwah yang disertai dengan humoris atau ketawa, hal tersebut dilakukan oleh $d a^{\prime} i$ Muhammadiyah untuk menarik perhatian jamaah yang mendengarkan dakwahn sekaligus untuk membuat para jamaah tidak mengantuk dan bosan dalam mendengarkan materi dakwah yang disampaikan oleh da'i Muhammadiyah, meskipun hal tersebut tidak banyak dilakukan dan diterapkan oleh da'i Muhammadiyah.

e. Model gabungan (serius dan humoris)

Model dakwah ini merupakan model dakwah yang menggabungkan model dakwah yang serius dengan model dakwah humoris, setiap $d a^{\prime} i$ Muhammadiyah akan menyesuaikan dengan materi, kalimat atau kata yang akan disampaikan, jika materi, kalimat atau kata merupakan hal-hal yang berkaitan dengan hal yang serius atau sangat penting seperti tentang Allah, Nabi, Malaikat dan lain-lain maka disampaikan dengan serius, namun jika materi, kalimat atau kata merupakan yang tidak terlalu serius maka biasa disampaikan dengan bahasa humoris. Model humoris dapat dilakukan dengan ketentuan sesuai dengan Al Qur'an dan Hadist.

Namun demikian berdasarkan hasil penelitian yang dilakukan oleh pendidikan Ulama Tarjih Muhammadiyah model dakwah yang lebih efektif digunakan oleh da'i Muhammadiyah di Kota Makassar adalah model $d a^{\prime} i$ yang serius namun materi dakwah yang disampaikan harus rasional dan kontemporer. Selain itu materi dakwah yang disukai oleh masyarakat adalah dakwah yang memiliki sentuhan sosial. Hal tersebut lebih di suka oleh masyarakat Kota Makassar yang modern dan rasional. 


\section{Materi Dakwah Muhammadiyah}

Hasyim, M. W. (2008) materi atau muatan dakwah itu ditujukan dan berproses secara langsung menyasar kepada pihak yang didakwahi. Menurut Mathar, J materi dakwah Muhammadiyah pada dasarnya, materi dakwah tidak lan adalah Al Qur'an dan Al Hadits sebagai sumber utama yang meliputi: aqidah, syariah, dan akhlak dengan berbagai macam cabang ilmu yang diperoleh darinya. Materi dakwah yang akan disampaikan oleh da'i Muhammadiyah di Kota Makassar belum terstruktur dengan baik, meskipun pada Tahun 2016 materi dakwah Muhammadiyah sudah dikelola dengan baik oleh Pusat Dakwah Islamiyah Muhammadiyah dengan cara memberikan tema dakwah dalam sebuah rencana dakwah yang akan disampaikan setiap khutbah jum'at dan ceramah pada saat Bulan Suci Ramadan, hal tersebut dilakukan agar tidak terjadi tumpang tindih materi dakwah yang akan disampaikan oleh $d a^{\prime} i$ Muhammadiyah. Namun demikian hal tersebut tidak dilakukan pada tahun 2017, materi dakwah yang disampaikan disesuiakan dengan kemampuan dan penguasaan materi oleh setiap $d a^{\prime} i$ Muhammadiyah. Namun demikian materi dakwah Muhammadiyah tetap berfokus pada permasalahan (1) Aqidah yaitu rububiyah dan uluhiyyah (2) Akhlak atau budi pekerti yang mengacu pada akhlak kepada Allah, akhlak kepada alam, akhlak kepada insan, (3) Ibadah sesuai tuntunan rasul yang mencakup aspek filsafat (4) Tarikh yang mencakup tarikh Rasul, Islam dunia, muamalah, Hadist, tasawuf, khalfah empat, Islam Indonesia, tafsir, ijtihad, jihad dan lain-lain (5) Kajian umum yang mencakup islam dan sains, islam dan sejarah, islam dan budaya, islam dan hukum, islam dan seni, islam dan politik, islam dan ekonomi, islam dan teknologi, islam dan filsafat, islam dan pendidikan, islam dan humaniora, islam dan astronomi, islam dan kesehatan, islam dan psikologi. (6) Kajian khusus mencakup islam dan wanita, islam dan pemuda, islam dan ekologi, islam dan etos kerja, islam dan ideologi, islam dan wiraswasta, islam dan hak asasi, islam dan kreatifitas, islam dan sekulerisme, islam dan hubungan Internasional, islam dan kemerdekaan, islam dan perubahan sosial, pendidikan Agama dan Kristologi. (7) Masail fiqhiyyah yaitu berbagai permasalahan yang muncul di tengah-tengah masyarakat, baik yang menyangkut masalah ibadah, aqidah, ekonomi, sosial, pangan, kesehatan, dan sebagainya seringkali meminta jawaban kepastiannya dari sudut hukum dan agama seperti dakwah melalui media sosial. Materi dakwah tersebut merupakan acuan atau pedoman dalam melakukan dakwah Muhammadiyah, sehingga setiap da'i Muhammadiyah dapat menyampaikan dakwahnya di tengah masyarakat sesuai dengan kemampuan dan kompetensi yang dimiliki. Materi dakwah tersebut didapatkan diberbagai sumber-sumber seperti buku, jurnal dan hasil penelitian, karena Salah satu aspek yang sangat penting bagi muballigh Muhammadiyah dalam mempersiapkan materi dakwah dan tablig adalah bagaimana mengambil sumber-sumber dan rujukan materi dakwahnya (Hidayat, S. 2007). Materi dakwah Muhammadiyah disampaikan oleh $d a^{\prime} i$ Muhammadiyah melalui berbagai cara seperti (1) Lisan, yaitu $d a^{\prime} i$ Muhammadiyah menyampaikan secara langsung kepada masyarakat, seperti ceramah, khutbah, pengajian, acara aqiqah (kelahiran anak), acara kematian (takziah), acara pertemuan dan acara syukuran, (2) Tulisan yaitu $d a^{\prime} i$ Muhammadiyah menyampaikan materi dakwah melalui tulisan seperti media WhatsApp, Line, facebook, BBM, Koran, Majalah. Secara umum dakwah Muhammadiyah dapat juga dikategorikan dalam dua bentuk yaitu dakwah yang terorganisir dan dakwah tidak terorganisir.

Pusat Dakwah Islamiyah Muhammadiyah khusus bidang majelis Tablig terus berupaya melakukan pemetaan kompetensi $d a^{\prime} i$ dengan materi-materi yang telah ditetapkan Pusat Dakwah Islamiyah Muhammadiyah, meskipun demikian ada beberapa $d a^{\prime} i$ yang tidak setuju dengan hal tersebut karena menganggap pemetaan seperti itu merupakan bentuk keraguan terhadap kemampuan yang dimiliki oleh $d a^{\prime} i$ Muhammadiyah, sehingga ada da'i Muhammadiyah yang tidak tunduk pada ketentuan yang diberikan oleh majelis Tablig Pusat Dakwah Islamiyah Muhammadiyah. Materi-materi dakwah perlu disistematisasikan dalam suatu 
rancangan sillabi dakwah berdasarkan kecenderungan dan kebutuhan mad'u. Para aktivis dakwah tidak boleh langsung menghakimi jamaah berdasarkan persepsinya sendiri, tanpa mempertimbangkan apa sesungguhnya yang sedang merekaalami (Astuti, D. 2006). Sehingga setidaknya ada empat unsur di dalam praktek dakwah, yakni pelaku dakwah $\left(d a^{\prime} i\right)$, penerima dakwah atau sasaran dakwah (mad'u), materi dakwah (pesan/ajaran Islam) dan media atau saluran dakwah (Fajrie, M. 2014).

\section{Peran Da'i Muhammadiyah dalam melakukan evaluasi kualitas aktifitas dan bentuk Dakwah Muhammadiyah di Kota Makassar.}

Tantangan $d a^{\prime} i$ Muhammadiyah di Kota Makassar sangat kompleks karena seorang $d a^{\prime} i$ memberikan ceramah atau khutbah kepada jamaah, audiensi masyarakat yang bersifat heterogen, sehingga membutuhkan berbagai kecerdasan dan keterampilan yang harus dimiliki oleh setiap da'i Muhammadiyah. Seperti halnya memberikan dakwah kepada masyarakat yang intelektual akan berbeda dengan masyarakat yang tidak berpendidikan, masyarakat yang miskin dan masyarakat kaya, masyarakat perumahan mewah dan masyarakat pemukiman kumuh dan lain-lain. Menurut hasil penelitian Abror, R. H. tahun (2014) bahwa kebangkitan dakwah dan kesuksesannya sangat ditentukan oleh kecerdasan, kesabaran dan keuletan para aktivis dakwah dalam menghadapi realitas sosial dan tantangan globalisasi, di samping komitmen keislaman sebagai basis ontologis aktivitas dakwah. Sehingga majelis Tablig Muhammadiyah selalu melakukan pengajian dan pelatihan kepada da'i Muhammadiyah, meskipun belum mendapatkan respons yang baik dari seluruh kalangan $d a^{\prime} i$ Muhammadiyah, seperti halnya dengan $d a^{\prime} i$ yang sudah senior, sudah tidak mau mengikuti pengajian dan pelatihan, salah satu penyebabnya adalah (1) faktor kesibukan (2) faktor kemalasan dan (3) tidak mau melakukan pembaharuan ilmu, (4) gengsi sosial. Pengajian dan pelatihan dilakukan untuk meningkatkan kualitas $d a^{\prime} i$ dan peran Muhammadiyah di masyarakat. Hal penelitian Rudianto, J atahun (2010) menunjukkan bahwa peran Muhammadiyah sangat penting dalam pengembangan pendidikan Islam di masyarakat dalam berbagai aspek kehidupan. Sehingga kompetensi $d a^{\prime} i$ Muhammadiyah yang diperlukan adalah:

a. Penguasaan Media Sosial

Pada era digital yang ditandai dengan perkembangan teknologi informasi dan komunikasi seperti sekarang ini, idealnya setiap da'i Muhammadiyah memiliki pemahaman dan mampu memanfaatkan media komunikasi untuk melakukan dakwah kepada masyarakat, seperti da'i yang memberikan ceramah pada bulan Ramadhan dengan menggunakan media komunikasi yaitu LCD, hal tersebut bukan hanya dilakukan oleh da'i muda atau yunior namun juga sudah dilakukan oleh da'i yang senior bahkan dilakukan oleh para kyai Muhammadiyah. Selain itu juga para $d a^{\prime} i$ Muhammadiyah diharapkan memberikan dakwah melalui media sosial seperti WhatsApp, Line, facebook, BBM, Koran dan Majalah. Muhammadiyah selalu tetap konsisten dalam melakukan gerakan dakwah amar ma'ruf nahi mungkar baik itu mengirimkan $d a^{\prime} i-d a^{\prime} i$ dan menerbitkan media cetak seperti jurnal Tablig, atau suara Muhammadiyah sebagai respons menjawab tantangan zaman di abad ke-2 Muhammadiayah ini (Tohari, T. 2011). Karena seiring dengan perkembangan teknologi yang semakin pesat, kegiatan dakwah amar ma'ruf nahi munkar bisa diseimbangkan dengan memanfaatkan media teknologi informasi (Fatmawati, A. 2010). Hal tersebut juga dikemukakan oleh Nafianti, D. (2012) mengoptimalkan media massa, baik hal tersebut berbentuk berita, opini dan artikel yang dapat diakses secara mudah oleh masyarakat luas.

b. Regenerasi $d a^{\prime} i$

Regenerasi da'i Muhammadiyah di Kota Makassar dilakukan oleh berbagai lembaga yang ada di bawah naungan Muhammadiyah seperti Pendidikan Ulama Tarjih Muhammadiyah melakukan pembinaan calon $d a^{\prime} i$, Pemuda Muhammadiyah yang selalu melakukan pelatihan dan pendidikan mubaligh, alumni 
Muhammadiyah khusus pada mahasiswa yang memiliki kemampuan dalam bidang dakwah seperti mahasiswa dari pendidikan Agama Islam, Komunikasi Penyiaran Islam dan Mahad Al-Birr, meskipun calon $d a^{\prime} i$ dari sumber ini masih sangat kurang salah satu penyebabnya karena mayoritas mahasiswanya adalah orang daerah sehingga jika sudah selesai menyelesaikan studi maka akan kembali ke kampung masing-masing. Eksistensi dari para da'i Muhammadiyah dan para ulama sangat penting sebagai salah satu elemen penting dalam penyebaran dakwah Muhammadiyah. Menurut hasil penelitian Purnomo, H. (2014) bahwa pendidikan dan pengajaran yang dilakukan oleh para $d a^{\prime} i$ dan ulama ulama Muhammadiyah sebagai elemen utama gerakan Muhammadiyah. Regenerasi $d a^{\prime} i$ bisa dilakukan melalui pelatihan mubaligh/mubalighat dan pembentukan korp mubaligh/mubalighat diharapkan dapat meningkatkan pemahaman kepada para mubaligh/mubalighat dan terjadi regenerasi yang berkelanjutan dari para mubaligh/mubalighat (Aziz, M. T. 2017). Sehingga yang terjadi adalah adanya regenerasi dalam Muhammadiyah secara konsisten dan berkelanjutan (Anshori, A., \& Hidayat, S. 2017).

\section{c. Pemahaman Peta Dakwah}

Peta dakwah merupakan kondisi sosial, ekonomi, politik, budaya disekitar wilayah dakwah, hal tersebut dilakukan oleh $d a^{\prime} i$ Muhammadiyah dengan cara melakukan observasi ke tempat-tempat dakwah dan melakukan wawancara (bertanya) dengan pengurus masjid mengenai kondisi jamaah di sekitar wilayah dakwah tersebut. Hidayat, R. (2014) peta dakwah, yaitu pemotretan seluruh potensi masyarakat di sekitar area medan dakwah yang dapat dijangkau secara obyektif dan rasional oleh da'i dimana dia berada, baik yang individu mapun kelompok. Peta dakwah secara nasional sebagai acuan dalam menjalankan kegiatan dakwah, membenahi manajemen dakwah persyarikatan secara tersistem/terorganisasi dengan baik (Arsam, A. 2010). Dengan informasi tersebut $d a^{\prime} i$
Muhammadiyah mampu memetakan dan mencocokkan materi dakwah dan model dakwah dengan kondisi masyarakat sekitar. Namun jika da'i Muhammadiyah tidak memiliki data tentang peta dakwah maka hal yang dilakukan adalah menyampaikan materi yang umum, singkat, padat dan tidak keluar dari Al Qura'an dan Al Hadist seperti materi dakwah aqidah. Sehingga pemahaman peta dakwah harus dimiliki setiap $d a^{\prime} i$, meskipun demikian peta dakwah Muhammadiyah belum sepenuhnya valid, hal tersebut terjadi karena peta dakwah Muhammadiyah di Kota Makassar belum sepenuhnya berdasarkan hasil penelitian yang dapat dipertanggung jawabkan kebenaran data-datanya. Berdasarkan data-data tersebut kemudian untuk dapat melakukan hal itu secara tepat sasaran, maka perlu diadakan analisis dan pengkajian tentang ruang lingkup dan unsurunsur dakwah secara komprehensif, sehingga kegiatan dakwah dapat berjalan secara terarah dan tercapai tujuan. Salah satunya melalui analisis SWOT. Berdasarkan analisis SWOT, kemudian perlu disusun dan diwujudkan menjadi peta dakwah. Hal itu kemudian menjadi dasar perencanaan dan pelaksanaan dakwah bagi da'i dan organisasi dakwah (Abdullah, A. 2012). Karena menurut hasil penelitian Syarifuddin, S (2012) majelis Tablig perlu mendesain peta dakwah yang sesuai dengan kebutuhan dan daya nalar masyarakat. Agar tujuan dari dakwah Muhammadiyah dapat tercapai dengan baik, karena salah

d. Efisiensi waktu

Da'i Muhammadiyah harus memiliki manajemen pengelolaan waktu dalam menyampaikan dakwah kepada masyarakat, karena khusus untuk dakwah di Kota Makassar, penyampaian materi dakwah hanya dianjurkan untuk menggunakan waktu 15 menit sampai 20 menit, sehingga materi dakwah yang panjang harus direvisi agar sesuai dengan waktu yang diberikan untuk menyampaikan dakwah, meskipun tidak ada yang melakukan protes secara langsung jika $d a^{\prime} i$ dalam menyampaikan materi dakwah melebihi waktu yang diberikan, 
namun demikian jamaah atau objek dakwah akan protes dalam hati atau gelisah dan merasa bosan. Konsep efisiensi dan efektifitas dalam aktivitas dakwah harus berusaha menyeimbangkan antara biaya, waktu maupun tenaga (Arsam, A. 2010).

e. Melakukan Kajian dan Membaca

$D a^{\prime} i$ Muhammadiyah harus selalu melakukan kajian kajian yang berkaitan dengan agama Islam atau kajian tentang Al Qur'an dan Hadist, agar setiap $d a^{\prime} i$ Muhammadiyah memiliki pemahaman dan ilmu yang sangat luas tentang agama Islam, selain itu $d a^{\prime} i$ Muhammadiyah harus memperbanyak membaca referensi seperti buku-buku, jurnal dan hasil penelitian agar mendapatkan berbagai ilmu pengetahuan yang kontemporer yang dapat menunjang pelaksanaan dan penyampaian dakwah kepada masyarakat. Seperti mengaitkan antara fenomena sosial, realitas sosial atau fakta sosial dengan Al Qur'an dan Hadist. Hal tersebut selain menambah referensi, semua $d a^{\prime} i$ dapat membuat buku, jurnal dan melakukan penelitian, agar dakwah $d a^{\prime} i$ Muhammadiyah selain menggunakan lisan juga menggunakan tulisan. Lebih dari itu dakwa Muhammadiyah dilakukan melalui amal usaha Muhammadiyah. Menghadirkan Islam selain dalam dakwah bilisan tetapi lebih penting lagi dalam dakwah bilhal dengan mendirikan berbagai amal usaha pendidikan, kesehatan, pelayanan sosial, pemberdayaan masyarakat, dan sebagainya (Jinan, M. 2011). Dan membuka majelis-majelis taklim yang dilaksanakan sekali seminggu, mendirikan sekolah-sekolah atau pesantren untuk mencapai misi Muhammadiyah (Daulay, M. 2015).

\section{KESMPULAN}

$D a^{\prime} i$ Muhammadiyah berdasarkan data dari majelis Tablig tahun 2017 jumlah da'i Muhammadiyah di Kota Makassar berjumlah 188 orang yang tersebar di seluruh wilayah di Kota Makassar yang tersebar di 133 Mesjid yang dikelola majelis Tablig dan hanya 31 merupakan masjid Muhammadiyah dan 102 yang bukan merupakan masjid Muhammadiyah. Untuk menjadi $d a^{\prime} i$ Muhammadiyah ada beberapa persyaratan yang harus dipenuhi yaitu (1) Merupakan kader Muhammadiyah, (2) Aktif dalam Organisasi Muhammadiyah, (3) Rekomendasi dari Pimpinan Ranting atau Cabang Muhammadiyah, (4) Lulus seleksi administrasi, (5) Lulus tes kemampuan membaca Al Qur'an dan tes kemampuan melakukan ceramah atau khutbah. Seluruh $d a^{\prime} i$ Muhammadiyah di Kota Makassar memiliki tingkatan klasifikasi sosial mulai dari low class, middle class dan higt class. Kompetensi yang harus dimiliki oleh $d a^{\prime} i$ Muhammadiyah yaitu (1) Memahami Al Qur'an dan hadits, (2) Memiliki ilmu pengetahuan dan pendidikan, (3) Mengikuti pelatihan. Bentuk model $d a^{\prime} i$ Muhammadiyah terbagi menjadi tiga bentuk yaitu model dakwah serius, model dakwah humoris dan model dakwah gabungan serius dan humoris. Materi dakwah muhammadiyah mencakup 7 materi yaitu aqidah, akhlak, tarikh, kajian umum, kajian khusus dan Masail fiqhiyyah.

\section{DAFTAR PUSTAKA}

[1] Abdullah, A. (2012). Analisis Swot Dakwah Di Indonesia: Upaya Merumuskan Peta Dakwah. MIQOT: Jurnal Ilmu-ilmu Keislaman, 36(2).

[2] Abror, R. H. (2014). Rethinking Muhammadiyah: Masjid, Teologi Dakwah Dan Tauhid Sosial (Perspektif Filsafat Dakwah). Ilmu Dakwah: Academic Journal for Homiletic Studies, 6(1), 5375.

[3] Afriza, M. F. (2016). Konflik Sosial Keagamaan Antara $\mathrm{Nu}$ dan Muhammadiyah: Studi Kasus Desa Nampu Kecamatan Gemarang Kabupaten Madiun. UIN Sunan Ampel : Surabaya.

[4] Amin, S. (2010). Pewarisan Nilai Sejarah Lokal Melalui Pembelajaran Sejarah Jalur Formal dan Informal Pada Siswa SMA di Kudus Kulon. Doctoral dissertation, Universitas Sebelas Maret.

[5] Anggariani, D. (2013). Politik Kekerabatan. Jurnal Politik Profetik, 2(2).

[6] Anshori, A., \& Hidayat, S. (2017). Manajemen Pendidikan Kader Muhammadiyah Dalam Pembentukan Akhlak Siswa (Studi Kasus di SMK Muhammadiyah 3 Surakarta dan SMK Muhammadiyah 4 Surakarta Tahun 2016/2017) 
(Doctoral dissertation, Universitas Muhammadiyah Surakarta).

[7] Anugrah, Dadan dan Kresnowiati, Winny. (2008). Komunikasi Antarbudaya: Konsep dan Aplikasi. Jakarta: Jala Permata

[8] Anugrah, Kresnowiati, (2008). Komunikasi Antarbudaya. Bandung: Jala Pratama

[9] Arsam, A. (2010). Manajemen dan strategi dakwah muhammadiyah kota semarang. Komunika, 4(2), 208-223.

[10] Arsam, A. (2010). Manajemen dan strategi dakwah muhammadiyah kota semarang. Komunika, 4(2), 208-223.

[11] Asroni, A., Yusup, M., \& Sofia, A. (2015). Dakwah dan Politik: Menakar Kontribusi Organisasi Islam Sayap Partai Politik Bagi Masyarakat Muslim Yogyakarta. Jurnal Dakwah, 14(1), 27-50.

[12] Astuti, D. (2006). Strategi Dakwah dalam Pelestarian Lingkungan Hidup.

[13] Azhar, A., Wuradji, W., \& Siswoyo, D. (2016). Pendidikan Kader dan Pesantren Muallimin Muhammadiyah Yogyakarta. Jurnal Pembangunan Pendidikan: Fondasi dan Aplikasi, 3(2), 113-125.

[14] Aziz, M. T. (2017). Korps Mubaligh/Mubalighat Muhammadiyah dan 'Aisyiyah Di Kecamatan Kadudampit Sukabumi. JURNAL SURYA, 2(1), 107-112.

[15] Daulay, M. (2015). Peran Organisasi Dakwah dalam Pelaksanaan Bimbingan dan Penyuluhan. HIKMAH: Jurnal Ilmu Dakwah dan Komunikasi Islam, 8(1), 98-106.

[16] Fahrudin, Fuad. (2009). Agama dan Pendidikan Demokrasi Pengalaman Muhammadiyah dan Nahdlatul Ulama. Jakarta : Pustaka Alvabet

[17] Fajrie, M. (2014). Metode Dan Strategi Dakwah Muhammadiyah Di Kabupaten Demak. Jurnal Komunikasi Islam AN-NIDA, 6(1).

[18] Fatmawati, A. (2010). Pelatihan Pemanfaatan Web Bagi Pemuda Muhammadiyah Cabang Kartasura.

[19] Hasyim, M. W. (2008). Dakwah Bertingkat Majalah Suara Muhammadiyah. Jurnal Dakwah, 9(1), 8197.

[20] Hidayat, M. (2008). Ormas Keagamaan Dalam Pemberdayaan Politik Masyarakat Madani (Telaah Teoritik-Historis). Komunitas; Jurnal Pengembangan Masyarakat Islam, 1.

[21] Hidayat, R. (2014). Strategipimpinan Daerah Muhammadiyah (Pdm) Pekanbaru Dalam Mengelola Wakaf Produktif (Doctoral dissertation, Universitas Islam Negeri Sultan Sarif Kasim Riau).

[22] Hidayat, S. (2007). Metode pengambilan sumber dan rujukan materi dakwah.

[23] Ilmi, M. (2013). Humor sebagai teknik dakwah: metode dakwah ceramah $\mathrm{hm}$. Cheng hoo djadi galajapo (Doctoral dissertation, UIN Sunan Ampel Surabaya).

[24] Isfironi, M. (2016). Proyek Identitas Kultur Kerukunan: Studi Harmoni Kehidupan Warga NU, Muhammadiyah dan LDII. Al-Adalah, 17(2).

[25] Jinan, M. (2011). Dinamika Pembaruan Muhammadiyah: Tinjauan Pemikiran Keagamaan.

[26] Karlina, N. (2014). Sejarah Dan Perkembangan Muhammadiyah Cabang Blimbing Daerah Sukoharjo (Doctoral dissertation, Universitas Muhammadiyah Surakarta)

[27] Kholis, M. (2015). Studi Komparatif Metode ljtihad Majelis Tarjih Dan Tajdid Muhammadiyah Dan Lembaga Bahtsul Masail Nahdlatul Ulama Mengenai Hukum Aborsi (Doctoral dissertation, Uin Sunan Ampel Surabaya).

[28] Lestari I P (2013) Interaksi Sosial Komunitas Samin Dengan Masyarakat Sekitar. Jurnal Komunitas. 5 (1) (2013) : 74-86.

[29] Mathar, J. Perbandingan strategi dakwah Muhammadiyah Nahdatul Ulama Ranting Sawangan Baru.

[30] Muhadi, N. (2013). Interaksi Sosial Antar Umat Muslim Dalam Keberagamaan (Studi Terhadap Interaksi Sosial Masyarakat Desa Giri Asih, Kabupaten Gunung Kidul, Yogyakarta : UIN Sunan Kalijaga

[31] Muhammadiyah, P. P. (2010). Keputusan Muktamar Muhammadiyah Ke 46 (Doctoral dissertation).

[32] Muttaqien, M. A. S. (2010). Komunikasi Antar Budaya: Study Pada Pola Komunikasi Masyarakat Muhammadiyah Dan NU Di Desa Pringapus, Semarang, Jawa Tengah.

[33] Nafianti, D. (2012). Tindak Tutur Perlokusi Dalam Dakwah Ustad Maulana Pada Acara "Islam Itu Indah" Di Transtv (Doctoral dissertation, Universitas Muhammadiyah Surakarta).

[34] Nawari Ismail. (2009). Interaksi Sosial. Yogyakarta : Universitas Muhammadiyah Yogyakarta.

[35] Purnomo, H. (2014). Sejarah Dan Perkembangan Muhammadiyah Cabang Kota Kudus Tahun 1920-2013 (Doctoral dissertation, Universitas Muhammadiyah Surakarta).

[36] Raharjo, S., \& Islam, J. S. D. K. (2008). Konflik Antara NU Dan Muhammadiyah (1960-2002).

[37] Rohmah, U. (2016). Interaksi Sosial Warga NU dan Muhammadiyah Studi Kasus di Desa Punduhsari. Journal of Government (Kajian Manajemen Pemerintahan dan Otonomi Daerah), 1(2).

[38] Rudianto, J. (2010). Peran Muhammadiyah dalam Pengembangan Pendidikan Islam Di Masyarakat (Pendekatan Sosiologis Di Desa Playen Playen Gunungkidul) (Doctoral dissertation, Universitas Muhammadiyah Surakarta). 
[39] Saifuddin, A. F. (1986). Konflik dan integrasi: perbedaan faham dalam agama Islam. Jakarta : Rajawali.

[40] Sariningrum, E. (2009). Hubungan Tingkat Pendidikan, Pengetahuan Dan Sikap Orang Tua Tentang Kebersihan Gigi dan Mulut Pada Anak Balita Usia 3-5 Tahun Dengan Tingkat Kejadian Karies Di Paud Jatipurno (Doctoral dissertation, Universitas Muhammadiyah Surakarta).

[41] Setiawan Iwan. (1999). Interaksi Sosial Antara Kelompok Tradisi Dan Reformis Islam Di Tingkat Desa (Studi Kasus Kelompok Pengajian Muhammadiyah dan kelompok Pengajian Nahdlatul Ulama (NU) di Desa Margasari, Kecamatan Margasari, Kabupaten Tegal, Provensi Jawa Tengah. Tegal : Institut Pertanian Bogor.

[42] Sujarwadi. (2010) Interaksi Sosial Antara Komunitas Pendukung NU dan Komunitas Pendukung Muhammadiyah (Studi Kasus Pada Masyarakat Kelurahan Danyang, Kecamatan Purwodadi, Kabupaten Grobogan), Semarang : Universitas Negeri Semarang.

[43] Susilowati, A. (2015). Integrasi Sosial Antara Penganut Nahdlatul Ulama Dan Muhammadiyah Di Desa Kendal Sewu Kecamatan Tarik Kabupaten Sidoarjo, UIN Sunan Ampel Surabaya).

[44] Sutarmo. (2005). Muhammadiyah Gerakan Sosial Keagamaan Modernis. Jogyakarta : Suara Muhammadiyah.

[45] Syafik-Nim, M. U. H. (2008). Relasi Sosial Ulama Nu Dan Muhammadiyah Pekalongan Dalam Proses Pasca Pilkada (Studi Kasus Gambar Mesum Qomariyah-Pontjo), Yogyakarta : UIN Sunan Kalijaga.

[46] Syahroni, A. A. (2015). Peta Stereotype dan Integrasi Agama: Studi Kasus Pemahaman Agama Antara Warga NU Dan Warga Muhammadiyah Di Desa Madulegi Kecamatan Sukodadi Kabupaten Lamongan, UIN Sunan Ampel : Surabaya

[47] Syam, N. (2003). Tradisi Islam Lokal Pesisiran: Studi Konstruksi Sosial Upacara Pada Masyarakat Pesisir Palang Tuban, Jawa Timur (Doctoral dissertation, Universitas Airlangga

[48] Syarifuddin, S. (2012). Teknologi Dakwah (Studi Analisis Penggunaan Teknologi Dakwah Muhammadiyah di Ambon) (Doctoral dissertation, Universitas Islam Negeri Alauddin Makassar).

[49] Thohari, Hajriyanto. (2005). Muhammadiyah dan Pergulatan Politik Islam Modernis. Cet 1. Jakarta: PSAP Muhammadiyah

[50] Tohari, T. (2011). Respons muhammadiyah terhadap kristenisasi di Indonesia.

[51] Wafik Ilzamul. (2012). Interaksi Sosial Antar Kelompok Islam (Studi Kasus NU dengan
Muhammadiyah di Desa Wisata Mlangi). Yogyakarta : Universitas Muhammadiyah Yogyakarta. 